\title{
Theory of Construction and Optimization of Equipment Course Focused on Practical Teaching
}

\author{
Jian-ming Wang ${ }^{1}$, Jing-de Huang ${ }^{1}$, Wei Liu ${ }^{1}$, Yue-qing Gao ${ }^{2}$ \\ ${ }^{1}$ Dalian Naval Academy, Dalian, 116018, china \\ ${ }^{2}$ Dongbei University of Finance and Economics, Dalian, 116025, china \\ Jdh925@sina.com
}

\begin{abstract}
Equipment course construction is an important basis for the implementation of practical teaching. According to the characteristics of course construction obedience training patterns and teaching mode, this paper analyses the construction idea of equipment course, and talks about the construction ways of equipment course, and studies on specific problems and measures of equipment course construction. In order to improve the practical training level of equipment course, improve the quality of personnel training, and provides scientific basis and theoretical support.

Index Terms - Practical Teaching, Equipment course, Course construction, Teaching reform

\section{Introduction}

Practical core course construction building is the base of disciplines construction building, curriculum construction process reflects prospective and applicability. Prospective is the key to the construction and development of the course, it is to keep the curriculum advanced and cutting-edge source of power. The reality is the course construction and development of the feasibility and operability, based on real-world applications is the basic prerequisite for the course requirements and the inevitable construction, lack of application of curriculum construction, inevitably difficult to implement or achieve their effect. With further promotion of military training transformation, equipment development must track and analyze the characteristics, , trying to break its contents, methods, forms and requirements in practice, to promote courses and equipment in accordance with the requirements of the combat ability to generate sustainable development.
\end{abstract}

\section{Basic Thinking of Curriculum Construction of Equipment}

Adhere to the major construction and curriculum construction as the ultimate goal, a reasonable construction of curriculum, curriculum development and implementation of research results to the quality of personnel training. According to "determine the course direction, highlighting the curriculum focus, maintain course features, accelerated curriculum development" ,with teaching staff construction as the basis, with curriculum development environment as the lead, with practice platform construction as the protection, to enhance the curriculum level as the focal point to form a good course system, incentive mechanism and the curriculum ecological environment ,to form the course construction ideas of "focusing on the quality of talent, focus on scientific research, focusing force characteristics, focusing on the practicing teaching" .

(1) Training to adapt to the new equipment development and demand of knowledge structure optimization, professional clear direction and characteristic of military talents as a general principle. Engaged in equipment related technology and management talents demands students to master the solid basic theoretical knowledge, have more skilled to begin speaking ability, has the strong ability of management and innovation spirit.

(2)Key course construction as the core, connotation with course construction as the main line, based on the construction of teachers team, adhere to the "behavior, preferring", " key construction is given priority to the general curriculum" principle, to ensure that the characteristics of curriculum in the teaching and research level and results in a major breakthrough.

(3)Create "high-quality" major by characteristic, advantage, implements the strategy of "brand". In continue to maintain the existing curriculum features and advantages, on the basis of accelerating the construction of key courses, course cross innovation to cultivate new growth points, further strengthening the construction of general courses; constantly promote the rapid development of the various related courses.

(4)Pay attention to the coordinated development, according to the course construction from set out actually, step by step, the principle of key construction. Pay attention to the teaching and scientific research, the coordinated development of the key courses and general courses. There are both teaching reform project and the quality monitoring. There is a mix of overall development goal and unit development plan.

\section{Technical Way of Curriculum Construction of Equipment}

\section{A. Position for Traction}

Equipment is the position of the foothold, equipment curriculum construction should be built around training talents, establishing high quality talents is the core of the curriculum construction and belonging. With the quality of personnel training to measure the comprehensive strength of running, talent training quality depends on the colleges teachers and curriculum construction level. For equipment classes, not high quality of theoretical education and practical training to cultivate high-quality new type of military personnel. Not advanced, reasonable, accord with internal requirement and law of specialized core curriculum system will not be able to 
set up a batch of in he enjoys a high reputation, the important influence of professional disciplines, difficult to implement a high level of education and training and it will be difficult to develop high quality new military personnel. Must arrange the position need on the curriculum construction of prominent position and priority, in order to promote the talents cultivation, course construction on the premise of training quality and military struggle, drive the curriculum construction, promote both into the orbit of virtuous circle , coordinated development and promotion.

\section{B. Power Scientific Research Development}

Scientific research is not only the energy dynamics of the development of the traction equipment, also can cause of the curriculum in basic theory of related equipment mutual fusion, permeate each other, improve together, it can promote between different techniques complement each other, complementary advantages, thus to drive the related equipment course and technology progress, development and renewal, promote the course construction level of ascension. Also, a high level of course also more conducive to concentrate superior forces to assume a number of major scientific research project, introduce more high level, creative scientific research. In the construction of curriculum, mainly pay attention to the following points: first, course construction must adapt to the development of military technology changes and course construction troops demand for talent. In real military struggle need improve the level of new equipment technology research projects and research, promote the transformation of scientific and technological innovation of reality to the forces fighting capacity, develop and promote the related curriculum and professional development. Second, to cultivate talents through to from the whole process of the transformation of scientific research project application to the achievements and make scientific research activities and closely integrated, harmonious coexistence. Third, equipped with full awareness courses construction level and scientific research is not a simple linear relationship, to play to teachers subjective initiative, will research through teaching, using teaching stimulate research background.

\section{Cross the Innovation as the Goal}

Innovation is the basic requirement of curriculum construction; only adhere to independent innovation, through the innovative practice, to promote the construction of curriculum, leading equipment class teaching construction and reform. Flexibly emphasis on independent innovation, however, does not exclude other colleges successful experience and practices, should actively introduce and absorb, connect with the actual to innovation, form their own innovations. From the most professional equipment course construction, many of them are using or learning theories and methods from other courses, to ensure our equipment classes its further development. That course cross innovation vitality, make the original discovered a new growing point. But Course cross is not in personnel, professional layout and the points of the courses in the form of the simple, joint or restructuring, follow the inherent logic and law of curriculum development, meet the needs of new equipment technology rapid development, more should reflect army information construction requirements, according to the construction of troops demand as the guidance, the development of new major, adjustment and reform the old major. For advantage course, characteristic course and promising course cross and penetration, with application and cross course is given priority to, really realize the intrinsic fusion between courses. At the same time, actively support and geared to the needs of new and high technology applied, for the military information construction of much-needed emerging and interdisciplinary courses, military science and technology to adapt to the rapid development of the reality of the needs and demands of talent forces changing the new situation.

\section{Specific Problems of Equipment Course Construction}

In solid first-class level of discipline echelon at the same time, reasonable structure and dynamic course echelon reserve force is also crucial. Equipment course construction should be emphasized to troops construction demand as the guidance, based on office post demand, capacity building as the core, outstanding practice, pay attention to the application of comprehensive, targeted to the curriculum, emphasizing on military struggle in urgent need of practical curriculum construction as the key point, increase the link in the construction of the courses of construction and management. Especially must strengthen education course system design, system of teaching material planning, practice platform construction and information resource system development, to promote the construction of equipment course global development.

\section{A. Course System Design}

Based on the position the education practice, focus on the course construction of characteristic development, by strengthening the existing curriculum resources integration, optimize the curriculum configuration, follow the equipment technology into curriculum development theory research, completes the course construction planning and design, professional around key construction course, key construction with troops are in urgent need of practical courses, course priority support advantage, form a complete set of coordinated development course, foster new curriculum, strengthening the military skills, military command, management and other professional basic construction, strive to build and forces close to actual combat training phase curriculum practice environment. Insist on equipment class curriculum construction "characteristic, targeted, advantage" development strategy, form the mutual fusion and innovation supporting system, the development of the curriculum group of professional group of construction pattern, flexibly firmly in position in the field of industry.

\section{B. Teaching Material System Planning}

Focus on the new theory of the development of new technologies, new equipment in combination with the practical 
training and information construction of equipment, in accordance with the "demand for education, highlight the high and new technology, outstanding comprehensive ability training" train of thought, renew the content of the teaching material system, implement the strategy of fine materials, concentrate on the key construction courses matching with backbone course teaching professional, publish a batch of representative curriculum professional level, reflect education characteristics of monographs, steadily push forward the new teaching methods of new training methods, form a threedimensional new education teaching material system.

\section{Practice platform construction}

Course construction tasks around the key equipment, a high starting point, high standard planning practice teaching platform development, optimize the combination simulation training equipment, realize the complementation of the various related equipment teaching material resource, play an overall resource allocation effect, manifested pays special attention to the professional characteristics of the construction of key laboratories and the teaching training base. Integrates the combat teaching, simulated training teaching; Reform of professional training, simulation digital simulation exercises; All the fighting positions professional scientific experimental implementation system operation. For the courses construction with scientific research conditions and provide professional teaching with practical teaching environment, promote the professional teaching gradually to simulated and visual direction.

\section{Information resources development}

Reinforcing the digital teaching environment construction such as the training of the campus network, multimedia network classroom and digital library. Built network teaching platform, strength the research and practice of network course teaching, automated teaching, multimedia teaching, online teaching and training, visual and intelligent three-dimensional information collection and query. Developed by making full use of multimedia teaching software and simulation training equipment, realistically simulate live-fire combat scenarios, regularly carry out the competition of modern education technology, and enhance the level of teaching and the effect of classroom teaching.

\section{Concrete Measures Of The Equipment Course Construction}

In accordance with the construction principle of "the outstanding professional characteristics, strengthening equipment application ", adhere to the organic combination of theory study and achievements transformation, the advantages and professional construction, course construction and course resources construction closely combined, promote professional and course construction by course advantage, through "a good professional, a good course, a good teaching material, a set of resources, a good system (standard monitoring, evaluation system)", the course construction and implementation of scientific research achievements Implement on the quality of personnel training, as shown in Figure 1.

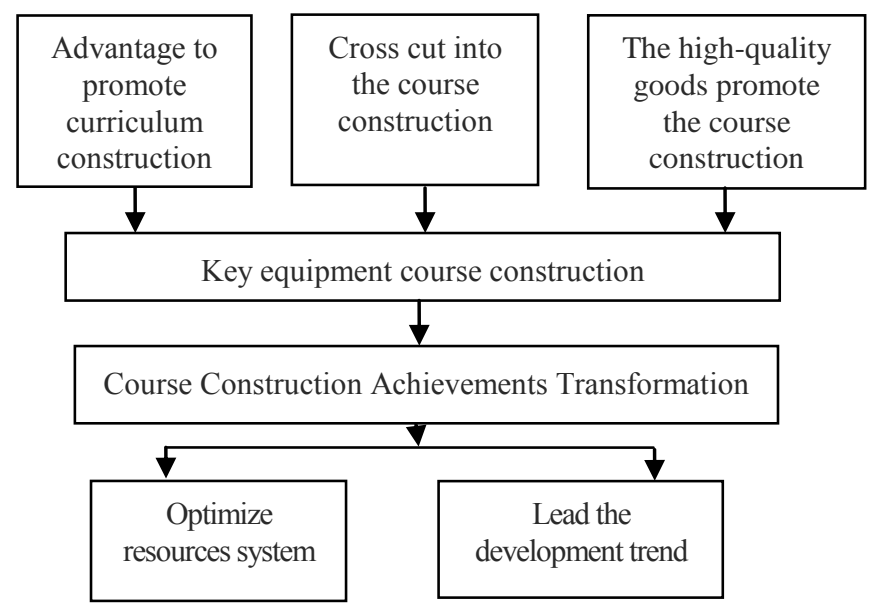

Fig. 1 Concrete measures of the equipment course construction

\section{A. Advantage to Promote Curriculum Construction}

Specialty construction is the key point of course construction, to correctly handle the relationship between curriculum and professional, characteristics and innovation, find the point of curriculum construction and professional construction, on the basis of giving full play to the advantages of equipment characteristics, pay attention to innovation. According to professional training and equipment the overall goal of the command and management of specialized personnel, focus on the needs of the position and the job requirements and professional specialty construction as the key of course advantage.

\section{B. Cross Cut into the Course Construction}

To highlight the characteristics of professional construction equipment course construction. Equipment course need to be able to reflect the latest scientific and technological achievements in the field of this course, especially reflect the troop's construction need of course, emerging results. Choose course construction reflected school education thought; meet the demand of troops and equipment development, improved students' ability of serving the core curriculum for key construction. To properly handle the relationship between series single course construction and course construction, by focusing on radiation from other equipment group of course construction, promote the key professional construction and development.

\section{High-quality Goods Promote the Course Construction}

Build up the high-quality goods consciousness, on the basis of the original teaching material planning at all levels; adhere to the principle of select of materials, to ensure high quality. Distinctive teaching materials into the classroom ensure the quality of teaching. Special fund to set up the teaching material construction, strengthen the awareness of cultivating new type of military personnel, which is based on curriculum reform development achievement, through the form 
of project construction of teaching material, writing published a batch of high quality and characteristic, strong adaptability of applied for education series teaching materials; Key support characteristic teaching material construction. Also should give attention to both high level talent training teaching material system construction, to avoid all levels training task with a textbook, or without appropriate teaching material is available.

D. Optimize Resources System by Key Course Achievement

To strengthen the construction of key curriculum resources, focus on transformation of curriculum construction achievements into high quality teaching resources. Improve the mechanism of the multimedia courseware, the network course construction. Multimedia courseware and the network curriculum is the carrier of equipment teaching plan, the excellent courses construction achievements into multimedia courseware and Internet courses, is to realize the curriculum construction in equipment to promote the ultimate goal of improving quality of teaching.

\section{E. Lead the Development Trend by Key Course Achievement}

In the process of the key course construction, through an organic combination of the course construction and scientific research, team construction, graduate student education and job training, give full play to the key course of the construction of the leading role, so as to promote the development of the general level of the course construction, drive the improvement of overall teaching quality.

\section{Conclusion}

Involves all aspects of the discipline construction, equipment course construction has a special importance in the professional development to improve the teaching quality of landmark. Only close to the post office needs, close to the actual need, close to the environment, close to the objects for construction of combat can output more excellent talents for the troops construction. Equipment course constructions only two-way meet universities and troops, to establish strengthening academic professional group of long-term mechanism and improve the quality of teaching.

\section{References}

[1] Ma DM,Xv M.Research and practice of professional practice teaching system. Dalian naval academy Journal,2009 (1).

[2] $\mathrm{Hu}$ J,Huang JD.The thinking of Strengthening practical teaching in the education . Liaoning normal university Journal,2012 (5).

[3] Meng QC.Attaches great importance to the guns professional practice, research the implement method of organization.Dalian naval academy Journal, 2012 (ADD). 